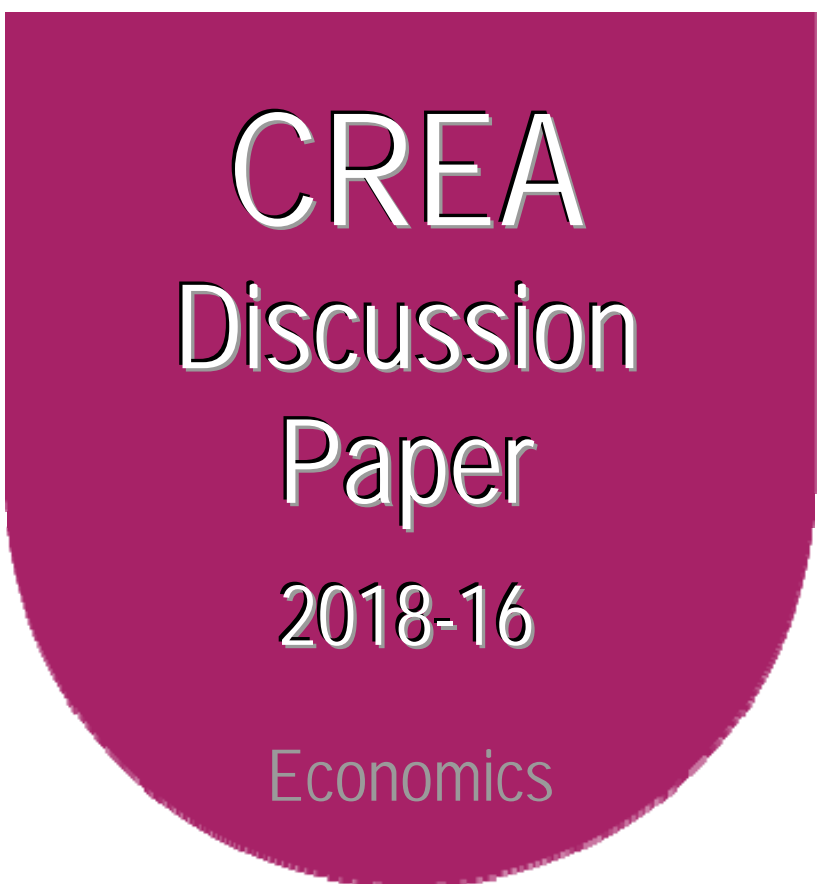

Center for Research in Economics and Management University of Luxembourg

\title{
The Asymmetric Experience of Gains and Losses in Job Security on Health
}

available online : http://wwwfr.uni.Iu/recherche/fdef/crea/publications2/discussion_papers

Anthony Lepinteur, INSIDE, University of Luxembourg

September, 2018

For editorial correspondence, please contact: crea@uni.lu

University of Luxembourg

Faculty of Law, Economics and Finance

$162 \mathrm{~A}$, avenue de la Faïencerie L-1511 Luxembourg 


\title{
The Asymmetric Experience of Gains and Losses in Job Security on Health
}

\author{
Anthony Lepinteur (University of Luxembourg)*
}

Monday $3^{\text {rd }}$ September, 2018

\begin{abstract}
Is workers' health more sensitive to losses than gains in job security? While loss aversion, whereby losses loom larger than gains, is typically examined in relation to decisions about anticipated outcomes, I first show using a large sample of workers from the European Household Community Panel and value-added models that losses in job security have a larger effect on health than equivalent job security gains. Second, I address endogeneity issues using the 1999 rise in the French Delalande tax as a quasi-natural experiment. It allows evaluating separately the causal impact of exogenous gains and losses in job security on workers' health. Difference-in-differences estimation results confirm that lower job security generates significant and robust losses in self-assessed health. Meanwhile a greater feeling of job security does not translate into a higher level of self-assessed health. These results are in line with the predictions of the model linking job security to health under the hypothesis of loss aversion built in this paper. This article also demonstrates that losses in health induced by lower job security are not transitory.
\end{abstract}

Keywords: Job Security, Self-Assessed Health, Loss Aversion, Difference-in-differences. JEL Classification Codes: I10, J28, J81.

${ }^{*}$ I am grateful to Michel Beine, Andrew Clark, Conchita D'Ambrosio and Giorgia Menta for useful comments. I gratefully acknowledges financial support from the Fonds National de la Recherche. 


\section{Introduction}

There is evidence in the literature that poor workers' health is an important predictor of loss in personal productivity and represents a serious cost to employers (Stewart et al. (2003a,b), Boles et al. (2004), Mills (2005), Mills et al. (2007), Burton et al. (2008)). Poor workers' health is also correlated with counter-productive behaviours such as absenteeism defined as the failure to report for scheduled work (Johns (2002), Duijts et al. (2007)) - and presenteeism - defined as attending work while ill (Biron et al. (2006), Caverley et al. (2007), Johns (2010)).

There is also a considerable amount of evidence showing that perceived job security and health are positively correlated (see Sverke et al. (2002) and Cheng \& Chan (2008) for two meta-analyses of the literature in occupational psychology). However, using cross-sectional data from 16 European countries László et al. (2010) produced mixed results. They did not find significant associations between job security and health in 7 countries. Nevertheless, most of the literature does not prove causation and is exposed to endogeneity issues such as reverse causation and omitted variable bias. Caroli \& Godard (2016) accounted for these issues using an instrumental variable approach. Once deriving weak-instrument-robust confidence intervals the impact of job security on self-assessed health and a set of objective health conditions turns out to be insignificant (although they showed that job security still affects significantly the probability to suffer from skin problems and headaches).

However, the literature assumed so far that the impact of job security on health is linear, i.e. that an increase and a decrease in job security of same magnitudes produce symmetric effects on health. But do gains and losses in job security really affect health in the same way? Boyce et al. (2013) demonstrated that loss aversion applies to the relationship between income and well-being: losses in income have a larger effect on well-being than equivalent income gains. To the best of my knowledge nothing is known about loss aversion, job security and health. 
This paper complements the existing literature by first building a theoretical model introducing loss aversion in job security. While loss aversion was originally theorized in the context of choices under uncertainty and applied to anticipated gains and losses (Kahneman \& Tversky (1979)), I follow Boyce et al. (2013) and apply the loss aversion hypothesis to actual changes in job security. The model developed in this paper predicts that empirical work neglecting the loss aversion hypothesis tend to overestimate the impact of gains in job security on health and underestimate the impact of losses.

Second, I use the European Community Household Panel (ECHP) to empirically test for the loss aversion hypothesis. Applying value-added models to a large sample of workers from different European countries I find that only losses in job security are significantly correlated with changes in self-assessed health. Gains in job security are not accompanied by changes in health on average. These results are in line with the predictions of the loss aversion hypothesis and are robust.

I finally use a natural experiment to assess separately the causal impact of an increase and a decrease in workers' job security on health. I focus on exogenous changes in the perceived job security induced by a French employment-protection reform implemented in 1999: an increase in the Delalande tax, which is paid by private-sector firms if they lay off workers aged over 50 in permanent contracts. This rise was restricted to firms with more than 50 employees, and as such provides a natural quasi-experiment that can be analysed via difference-in-differences estimation. Georgieff \& Lepinteur (2018) demonstrated that the rise in the Delalande tax increased the perceived job security of workers aged over 50 at the cost of higher levels of perceived job insecurity of their younger colleagues in the treated firms. I take benefit of the direct impact of the reform on protected workers and its spillover effects on unprotected workers to estimate separately the causal impact of an exogenous increase and an exogenous decrease in job security on self-assessed health. The difference-in-differences estimates confirm that changes in the job security produce asymmetric changes in workers' health. The reduction in job security of unprotected workers reduced the level of self-assessed 
health while the increase in job security of protected workers did not affect their health significantly.

There are different issues that the difference-in-differences needs to address. It first need to rule out potential confounding French reforms. In 1998, the French Ministry of Labour announced that there would be a reduction of standard weekly hours from 39 to 35 hours in firms with over 20 employees; this reform was enacted in 2000. These expected changes may therefore have affected perceived job security in firms with over 20 employees in the ECHP data from 1998 onwards. I however show that estimates remain unchanged when we drop workers from firms with under 20 employees (i.e. when we restrict the sample to include only firms that were subject to the 35-hour week). Second, macro-economic trends may produce different changes in job security in large and small firms. I address this issue by taking advantage of the cross-country dimension of ECHP data. I replicate the identification strategy in bordering countries and show that the difference-in-differences estimates there are insignificant.

Little is known about how workers health adapts to changes in job security (Green (2015)). This paper contributes to the literature by estimating the long-run effects on health of the changes in perceived job security induced by the 1999 rise in the Delalande tax. The results show that the health of unprotected workers did not adapt to the reduction in job security even three years after the reform.

The remainder of this paper is organized as follows. Section 2 presents a theoretical model where health is a function of job security. I then introduce loss aversion in job security and show how the models assuming a linear relationship between job security and health are biased and how the literature in occupational psychology and economics can be reconciled. Section 3 describes the ECHP data while the Section 4 presents evidence of the loss aversion hypothesis using a large sample of European workers. The Section 5 describes the institutional background of the 1999 rise in the Delalande tax as well as the identification strategy used to estimate the causal impacts of gains and losses in job security on health. The main results, 
the robustness checks and the evidence on adaptation appear in the same Section. Section 6 concludes.

\section{Loss Aversion in Job Security: Theoretical and Empirical Implications}

Loss aversion has been first formalized by Kahneman \& Tversky (1979) as a bias in information processing. It represents the idea that anticipated losses have a greater influence on choice and predicted feelings about an outcome than anticipated gains of the same magnitude. Loss aversion was first applied to the study of choice under uncertainty (Kahneman \& Tversky (1979)), but it has since been shown to be applicable across a range of real-world contexts (see Table 5.1 in Camerer et al. (2000)). Rick (2011) reveals that when actual losses take place, they have no greater effect than equivalent gains. Loss aversion can be then considered as a decision-based error. An established argument is that people are subject to affective-forecasting errors, according to which they overestimate the intensity of the negative feelings they expect to experience when suffering a loss. Consistently with this argument, evidence of loss aversion may not be detected for losses actually experienced rather than merely anticipated (Gilbert et al. (2004), Kermer et al. (2006)).

I follow Boyce et al. (2013) by asking whether loss aversion applies to actual losses and gains in job security, as opposed to anticipated losses and gains. I assume that individuals perceive their actual level of job security denoted by $S$ and one level of job security of denoted by $\bar{S}$ as a reference point. Then, gains (losses) in job security $\Delta S$ are defined as the distance between $S$ and $\bar{S}$ if $S$ is greater (lower) than $\bar{S}$. The reference point $S$ is also referred as the status quo and is defined at the individual level.

I assume that that there exists a function $h(\Delta S)$ reflecting the impact of changes in job

security on health with $\frac{\partial h(\Delta S)}{\partial \Delta S} \geq 0$ and $h(0)=0$. The observed health of an individual $H(S)$ 
is expressed as follows:

$$
H(S)= \begin{cases}\lambda_{1} h\left(\Delta^{g} S\right), & \text { if } S>\bar{S} \\ \lambda_{2} h\left(\Delta^{l} S\right), & \text { if } S \leq \bar{S}\end{cases}
$$

where $\lambda_{1}$ and $\lambda_{2}$ are respectively the weights associated to gains $(S>\bar{S})$ and losses $(S \leq \bar{S})$ in job security. The loss aversion hypothesis implies $\lambda_{2}>\lambda_{1} \geq 0$

Neglecting the loss aversion hypothesis and assuming that the relationship between job security and health is linear biases empirical estimations. A standard linear model has the following structure:

$$
H(S)=\lambda h(\Delta S), \quad \text { for any } S
$$

In such model, $\lambda$ is simply the weighted average of the effects of gains and losses in job security:

$$
\lambda=n_{1} \lambda_{1}+\left(1-n_{1}\right) \lambda_{2}
$$

where the total number of workers has been normalized to 1 and $n_{1}$ and $1-n_{1}$ are respectively the share of workers experiencing gains and losses in job security. The loss aversion hypothesis implies that $\lambda_{2}<\lambda<\lambda_{1} \geq 0$ for $n_{1} \in(0 ; 1)$. This means that a linear model tend to underestimate the effect of losses in job security and overestimate the effect of gains in job security on health.

Some articles in the literature based on linear econometric models do not to identify significant relationships between job security and health (László et al. (2010), Caroli \& Godard (2016)). However, the loss aversion hypothesis may explain insignificant linear correlations between health and job security. $\lambda$ is an increasing function of $\lambda_{1}$ and $\lambda_{2}$ and a decreasing function of $n_{1} \cdot{ }^{1}$ Consequently, $\lambda$ decreases and tends to zero when $\lambda_{1}$ tends to zero (i.e. when gains in job security are poorly correlated with health) and when $n_{1}$ tends to one (i.e when the number of workers experiencing gains in job security is relatively high compared to workers experiencing losses) whatever the value of $\lambda_{2}$. The different results per country

\footnotetext{
${ }^{1} \frac{\partial \lambda}{\partial n_{1}}=\lambda_{1}-\lambda_{2}<0$.
} 
in László et al. (2010) may be explained by the different combinations of $\left(\lambda_{1}, \lambda_{2}, n_{1}\right)$ at the national level.

The remaining of this paper aims at testing empirically whether the loss aversion hypothesis does apply to the relationship between job security and health.

\section{Data}

The estimation samples come from the European Household Community Panel (ECHP). The ECHP is a longitudinal survey carried out in 14 European countries. A nationally representative sample of household and individuals was interviewed each year between 1994 and 2001 in each country. The ECHP contains detailed information on socio-economic characteristics, incomes, employment conditions, social relations and so on. ${ }^{2}$.

I use self-assessed health as main dependent variable. This is measured in the ECHP by the following question: "How is your health in general?". Respondents answered on a 5-point scale: "Very bad", "Bad", "Fair", "Good" and "Very Good". Self-assessed health is one of the most popular health measures in research. Responding to concerns about interpretation and reporting biases, Doiron et al. (2015) recently review the literature illustrating the predictive power of this measure on mortality, risk of coronary heart diseases or chronic diseases. They also demonstrate that self-assessed health predicts future health outcomes such as hospitalizations and prescription drugs using an Australian survey data linked to administrative individual medical records. According to Doiron et al. (2015), the predictive power of self-assessed health is particularly precise in case of serious and chronic diseases.

To measure individual job security, I use the following question: "How satisfied are you with your present job in terms of job security?". Respondents answered on a 6-point scale, 1 meaning "Not Satisfied" and 6 meaning "Fully Satisfied". This measure of perceived job security has already been used by the literature (Clark \& Postel-Vinay (2009), Georgieff \&

\footnotetext{
${ }^{2}$ More details are available on http://ec.europa.eu/eurostat/web/microdata/european-communityhousehold-panel. [Last accessed 18 December 2017]
} 
Lepinteur (2018)) and is a strong predictor of individual choices such as future job quits (Clark (2001)).

\section{The Hypothesis of Loss Aversion in Job Security across Eu- rope}

\subsection{Empirical Strategy}

I follow Boyce et al. (2013) and test the loss aversion hypothesis using the following valueadded model:

$$
H_{i t}=\alpha_{0}+\alpha_{1} H_{i t-1}+\alpha_{2} \Delta S_{i t}+\alpha_{3} \Delta S_{i t} * L_{i t}+\alpha_{4} X_{i t}+\epsilon_{i t}
$$

where $H_{i t}$ and $H_{i t-1}$ stand for the self-assessed health of the worker $i$ at year $t$ and $t-1$. $\Delta S_{i t}$ represents the change in perceived job security between $t$ and $t-1$ while $L_{i t}$ is a dummy indicating whether the $\Delta S_{i t}$ is a loss. Equation 1 is estimated using OLS. I first estimate this model without incorporating loss aversion $\left(\alpha_{3}=0\right)$. Next, I model loss aversion by allowing the slope coefficient $\left(\alpha_{3}\right)$ to differ whether workers experienced losses or gains in perceived job security over the previous year. The effect of a gain in job security is captured by $\alpha_{2}$ while the effect of a loss in job security is equal to $\alpha_{2}+\alpha_{3}$. The loss aversion hypothesis predicts that $\alpha_{3}$ is positive and significantly different from zero.

This specification implies that the reference point $\bar{S}$ of an individual is her level of perceived job security in $t-1$. This hypothesis is consistent with the literature showing that individuals use their past job characteristics as reference point for comparison purposes (Clark (1999), Grund \& Sliwka (2007), Di Tella et al. (2010), Lepinteur (2018)).

The relationship between $H_{i t}$ and $\Delta S_{i t}$ will not be causal if there is an omitted variable $\mathrm{Z}$ that simultaneously predicts health in $t$ and the change in job security between $t-1$ and $t$. I estimate a value-added model controlling for health at $t-1$ to rule out this channel. The intuition is that any time invariant omitted variable $\mathrm{Z}$ that predicts both health at $t$ and 
change in job security between $t-1$ and $t$ will be picked up by health at $t-1$.

The estimation sample here consists of workers between 20 and 60 years old coming from 11 European countries, working in the private sector and for whom perceived job security, self-assessed health and control variables are available for 2 consecutive years. Luxembourg, Germany and the U.K. are not part of the sample because of insufficient observations due to missing values. This estimation sample includes 272,016 observations (55,657 individuals). Figure 1 depicts the distribution of self-assessed health and perceived job security. Most of the workers reports "Good" level of health while more than $70 \%$ of the estimation sample reports perceived job security of at least 4 over 6 . Additional descriptive statistics can be found in Table A.1 and the distribution of changes in job security is reported in Figure A.1.

\subsection{Main Results}

Table 1 shows the estimates for the Equation 1. Column (1) shows a positive and significant linear relationship between changes in perceived job security and health. A 1-unit rise in perceived job security (on a 6 -points scale) between $t$ and $t-1$ is accompanied by a $0.022-\mathrm{SD}$ rise in self-assessed health in $t$. By assumption, a 1-unit decrease in perceived job security is also accompanied by a $0.022-\mathrm{SD}$ decrease in health.

Column (2) now differentiates between gains and losses in job security. This column shows that gains and losses have different effects on health since $\alpha_{3}$ is significantly different from 0 . The estimates suggests that experiencing a 1-unit increase in perceived job security produces no significant changes $\left(\alpha_{2}=0.001\right)$ in health while a loss of the same magnitude reduces health by $0.044-\mathrm{SD}\left(\alpha_{2}+\alpha_{3}\right) \cdot{ }^{3}$ Allowing for loss aversion in the relationship between job security and health also improves the quality of the fit as revealed by the higher adjusted $R^{2}$ in Column (2). Figure 2 traces out an implied functional relationship between changes in health and job security using the results from Columns (1) and (2). It graphically illustrates how studies not

\footnotetext{
${ }^{3}$ I included individual fixed-effects in an alternative specification and results remain unchanged. Nevertheless, while the inclusion of the individual fixed-effects controls for the influence of time-invariant factors they also expose the estimates to the Nickell's bias (Nickell (1981)) which may be a plausible threat regarding the limited number of observations per individual in ECHP (at most 8 observations).
} 
allowing for loss aversion (dash line) may overestimate the effect of a gain and underestimate the effect of a loss in job security compared to a specification allowing for loss aversion (solid line). ${ }^{4}$

\subsection{Robustness Checks}

Equation 1 assumes that the impact of gains and losses may be different but they remain linear. I relax this assumption by adding interactions terms. The results in Column (3) show that the quadratic terms do not attract significant estimates and the quality of the fit measured by the adjusted $R^{2}$ does not increase. While gains and losses impact health differently, their effect remains linear.

I also allow the intercept to differ if workers experienced a loss in job security as in Boyce et al. (2013) by adding a dummy equals one in case of loss in job security. Results in Column (4) remain unchanged.

The model presented in Section 2 assumes that health is influenced by changes in job security and does not depend on the level of job security. However the results in Column (2) may also confound the impact of the level of job security. I control in Column (5) for job security in $t$ and results remain the same.

Table A.2 asks whether the loss aversion hypothesis is verified in all the countries in the estimation sample. The results show that the losses in health associated to losses in job security are always significantly bigger than the effects induced by gains in job security of similar magnitude. In some countries (France and Italy), gains in job security are accompanied by significant increases in self-assessed health while in 8 countries (The Netherlands, Belgium, Ireland, Spain, Portugal, Finland, Greece and Denmark), there is no significant relationship between gains in job security and health. All the estimates confirm the prediction of the loss

\footnotetext{
${ }^{4} 60,852$ and 55,864 individuals respectively report gains and losses in job security. The effect of a gain in job security is equal to 0.001 and the effect of a loss is equal to 0.044. According to the notations used in Section $2, n_{1}=0.52, \lambda_{1}=0.001$ and $\lambda_{2}=0.044$. The model in Section 2 predicts a linear trend $\lambda$ equal to $n_{1} \lambda_{1}+\left(1-n_{1}\right) \lambda_{2}$. This implies that $\lambda$ is equal to $0.521 * 0.001+(1-0.521) * 0.044=0.022$. This result is consistent with the estimated linear trend in column (1) of Table 1.
} 
aversion model: the slope of losses in job security is significantly more steeper than the slope of gains in job security (except in Finland).

The ECHP stopped in 2001 and these results may not hold for more recent periods. To address this issue I replicated the regressions of this section on more recent European panel datasets (the German Socio-Economic Panel and the British Household Panel Survey). Results in Table A.3 confirm that the loss aversion hypothesis holds for more recent periods and in European countries not covered by the ECHP (1994 to 2014 in Germany and 1997 to 2008 in the U.K.). All the regressions of this Section were replicated using ordered models and results are unchanged.

While results in Table robustly 1 support the loss aversion in job security hypothesis, they do not prove causation. Value-added models do not control for the influence of time varying omitted variables that may spuriously drive changes in perceived job security and health. They do not rule out concerns of reverse causality either. Estimating the causal impact of perceived job security under the assumption of loss aversion requires to identify a source of exogenous variation in job security. The next section proposes to exploit a French quasinatural experiment to assess the causal impact of gains and losses in perceived job security on health.

\section{The Causal Effect of a Loss and a Gain in Job Security on Self-Assessed Health}

\subsection{Institutional Background, Identification Strategy and Estimation Sam- ple}

The Delalande tax was proposed and introduced in the French legislative system in 1987 to restore the financial balance of the unemployment-insurance system and reduce the rise in the layoffs of older workers. Despite numerous changes over time, the principle of the tax has remained unchanged: firms laying off workers of over a certain age have to pay the Delalande 
tax to the unemployment-insurance system. This tax is proportional to the worker's gross wage and covers private-sector workers with permanent contracts. From 1987 to 1992, the tax amount was three months of gross wages for all workers aged over 55.

The first major changes to this tax were introduced in July 1992. Table 2 shows how the tax profile has changed. In particular, in 1992 the tax started to depend on firm size, the age threshold of workers covered was lowered to 50, and the maximum tax amount increased to 6 months of gross wages. However, workers who were hired after age 50 and had been unemployed for at least 3 months were exempt from the tax. Additional changes to the tax scheme were made in January 1993 and January 1999. From 1993 to December 1998, the tax did not depend on firm size but only on the worker's age.

This article focuses on the last change to the tax. In January 1999, the tax was increased for firms with over 50 employees only. The tax was equal to 2 months of gross wages for 50 years old workers and reached 12 months of gross wages for workers between age 56 and 57 . This tax represents an important share of the total separation costs: Behaghel et al. (2004) estimate for instance the average French separation costs to be equal to almost 4 months of gross wages while Abowd \& Kramarz (2003) estimate these costs to be equal to 5 to 7 months of gross wages.

This change provides a natural quasi-experimental design for difference-in-differences (Di-D) specifications. I propose first to estimate the following D-i-D equation using ordinary least square with individual fixed-effects:

$$
H_{i t}=\alpha_{1} R e f_{i t}+\alpha_{2} X_{i t}+\mu_{i}+\lambda_{t}+\epsilon_{i t} .
$$

$H_{i t}$ refers to the self-assessed health of worker $i$ at time $t$ and $X_{i t}$ is a vector of standard controls. Refit corresponds to the interaction between the variables Treat $_{i}$ and Post . Treat $_{i}$ equals 1 for worker $i$ employed in treated firms ( $\geq 50$ employees) and 0 for workers in nontreated firms (<50 employees). Post $t_{t}$ is a dummy equal to 1 after January 1999. $\alpha_{1}$ captures 
the impact of the reform in the treated firms. Equation 2 includes individual fixed effects $\mu_{i}$ that pick up unobserved time invariant individual heterogeneity and year fixed effects $\lambda_{t}$. I

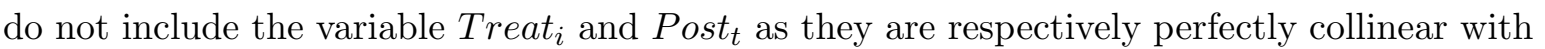
the individual fixed effects and the year dummies. ${ }^{5}$

Equation 2 does not account for the age of workers in treated firms and as such $\alpha_{1}$ reveals the population effect of the treatment. However, using a stochastic job-matching model that accounts for the Delalande tax, Behaghel (2007) shows that the change to the tax in 1999 is likely to both reduce the separation rate and the probability of a return to work for older workers, while it increases the separation rate and reduces the probability to return to work for younger workers. Georgieff \& Lepinteur (2018) recently confirmed these conclusions by demonstrating that older workers felt more protected after the reform while younger workers in treated firms perceived a significant increase in job insecurity.

I then separate the impact of the reform between older and younger workers, and estimate the following equation:

$$
H_{i t}=\beta_{1}\left(R e f_{i t} * P_{i}\right)+\beta_{2}\left(R e f_{i t} * U_{i}\right)+\beta_{3} X_{i t}+\mu_{i}+\lambda_{t}+\epsilon_{i t}
$$

Equation 3 is the counterpart of Equation 2, except that I now interact the treatment with the following dummy variables: $P_{i}$ and $U_{i}$, standing respectively for protected and unprotected workers. As such, $\beta_{1}$ in Equation 3 isolates the effect of job protection on the self-assessed health of older workers protected by the tax while $\beta_{2}$ analogously picks up any effect on unprotected younger workers in treated firms.

The 1999 rise in the Delalande tax was announced by the French government one year beforehand and the reintroduction of firm size discontinuity was publicly known months by the end of 1998. This means that employers may have strategically adjust their labour

\footnotetext{
${ }^{5}$ The D-i-D equation with individual fixed-effects used in this Section does not affect the nature of the job security of reference $\bar{S}$ (it remains an individual past value of job security) but implies a change in its measurement. It is not anymore the individual job security in $t-1$ but it is the individual average level of job security prior to the implementation of the reform.
} 
demand before the implementation of the law. Georgieff \& Lepinteur (2018) identified these anticipation effects by showing that employers in treated firms laid off relatively more workers just after the announcement of the reform but before its implementation.

To account for anticipation effects, I finally estimate the Equations 4 and 5:

$$
H_{i t}=\gamma_{1}\left(R e f_{i t} * P_{i}\right)+\gamma_{2}\left(R e f_{i t} * U_{i}\right)+\gamma_{3}\left(A n t_{i t} * P_{i}\right)+\gamma_{4}\left(A n t_{i t} * U_{i}\right)+\gamma_{5} X_{i t}+\mu_{i}+\lambda_{t}+\epsilon_{i t}
$$

$$
H_{i t}=\delta_{1}\left(\operatorname{Tot}_{i t} * P_{i}\right)+\delta_{2}\left(\operatorname{Tot}_{i t} * U_{i}\right)+\delta_{3} X_{i t}+\mu_{i}+\lambda_{t}+\epsilon_{i t}
$$

The variable $A n t_{i}$ in Equation 4 captures the anticipation effects by interacting the variable Treat $_{i}$ with the 1998 year dummy. If there were no anticipation, $\gamma_{1}$ and $\gamma_{2}$ should be respectively equal to $\beta_{1}$ and $\beta_{2}$ while $\gamma_{3}$ and $\gamma_{4}$ should be equal to zero, and considered as placebo tests. However, Georgieff \& Lepinteur (2018) already confirmed that the perceived job security of workers in treated firms already changed in 1998. In case of anticipation, $\beta_{1}$ and $\beta_{2}$ will be biased towards zero and $\gamma_{1}$ and $\gamma_{2}$ will provide more accurate estimates of the treatment effects.

Tot $_{i t}$ in Equation 5 is a dummy equal to 1 if the individual $i$ is working in a treated firms from 1998 onwards. Equation 5 is similar to Equation 3 except that it also accounts for the effects of the changes in perceived job security induced by the announcement of the reform and the strategic adjustment in labour demand of the employers.

The rise in the Delalande tax in 1999 only applied to workers aged over 50 in firms with over 50 employees. I identify the covered respondents in the ECHP by their reported age in the survey (misreporting is corrected by comparing birth and interview dates). The size of the firm in which the respondent works, measured by the number of employees in the firm, is recorded in the following categories:: "None", "1 to 4", "5 to 19", "20 to $49 "$ ", "50 to 99", "100 to 499 " and "500 or more". This allows distinguishing treated from non-treated workers.

The main sample consists of adult respondents working in the private sector with per- 
manent contracts, and with valid information on job characteristics, perceived job security and self-assessed health. I restrict the sample to workers aged between 40 and 58 who do not cross the age 50 threshold during the post-treatment sample period (i.e. who were born before September 1949 or after December 1951), and who were hired when under 50. To avoid the issue of self-selection into the treatment, I exclude employees who switch from a large (small) to a small (large) firm, and those who stay in the same firm but report a change in its size between 1998 and 2001. Table A.4 presents some descriptive statistics of the estimation sample.

Figure 3 shows the distribution of self-assessed health and perceived job security. It can be seen that $80 \%$ of responses are "Fair" or "Good" health while the perceived job security has negative skewness: $70 \%$ of the responses are 4 and 5 .

\subsection{Main Results}

Columns (1) and (2) of Table 3 estimate respectively the population effect and the treatment effects separately for the protected and unprotected workers on self-assessed health. ${ }^{6}$ The population effect is equal to zero: this is consistent with the null population effect on perceived job security, e.g. the absence of significant departures from the status quo (see Column (1) of Table A.5) should not translate into significant changes in health. None of the estimates in column (2) are significantly different from zero. However, those estimates may be biased towards zero in case of anticipation effects. Columns (3) and (4) report the treatment effects while anticipation are accounted for. The results show that the increase in perceived job security of protected workers did not produce an increase in their health. Nevertheless, the reduction in job security of unprotected workers did reduce their health by

\footnotetext{
${ }^{6}$ The estimation sample being different from Georgieff \& Lepinteur (2018) I replicate their empirical strategy in Table A.5 and confirm their results: older workers benefited from the reform, while the job security of younger workers fell (see Column (2)). As the share of unprotected and protected workers in the sample is balanced the population effect in Column (1) is equal to zero. Column (3) asks then whether protected and unprotected workers anticipated the implementation of the reform since the reform was announced months ahead before 1999. While the point estimates for anticipation in Column (3) are not statistically significantly different from zero, they are of the same sign of the treatment effect and support the existence of anticipation effect.
} 
0.147 standard deviation. As in Georgieff \& Lepinteur (2018), I find significant anticipation effects for unprotected workers in $1998 .^{7}$

The estimates in Columns (3) and (4) indicate that an increase in job security does not translate into better health but a significant loss in job security worsens health. This is consistent with the loss aversion hypothesis and with the results presented in the Section 4. The total effects on perceived job security being statistically equal between protected and unprotected workers in absolute terms (see Column (4) of Table A.5) I can directly test for the loss aversion hypothesis by checking that the absolute effects on health are significantly different in column (4). A Wald test rejects the equality of the coefficients at the $10 \%$ level and confirms the loss aversion in job security.

One of the requirements for $\mathrm{D}$-i-D estimation to yield causal effects is that there is a common trend in self-assessed health in the control and treatment groups prior to the policy change. Figure 4 plots mean self-assessed health over time and Figure 5 plots the same statistics but splitting the treatment groups into protected and unprotected workers. The trends in the treatment and control group are fairly similar pre-treatment, which provides support for the common-trend assumption. The residuals of the health regressions (not reported) also present similar trends. I also carry out placebo regressions to test the commontrend assumption. In the placebo experiment I assume that the change in the Delalande tax scheme came into force in 1997. The point estimates in column (5) of Table 3 are statistically insignificant for all groups, and confirm the common-trend assumption.

\subsection{Robustness checks}

For ease of reading robustness checks are performed on the Equation 5 (estimates in the Column (4) of Table 3).

\footnotetext{
${ }^{7}$ I also explored the same source of heterogeneity as in Georgieff \& Lepinteur (2018) (gender, education and wage quartile) and did not find significant differences.
} 


\subsubsection{Ruling Out Confounding Factors}

In 1998, the French Ministry of Labour announced a reduction in the standard workweek from 39 to 35 hours in companies with more than 20 employees. This may have affected worker's self-assessed health in those firms. To ensure that the main results on health following the Delalande tax are not picking up this other reform, I re-run the baseline regression excluding workers in firms with under 20 employees. The results appear in Column (1) of Table 4 , and are consistent with the baseline results. ${ }^{8}$

The measures of job security and health being both self-reported, one may fear that unobserved time varying factors may affect simultaneously self-reported measures. Nevertheless, those unobserved time varying factors should also affect the other self-reported measures of the survey. The ECHP contains a module on satisfaction with respect to four dimensions of life: job, housing, financial situation and leisure. I re-run the baseline regression using those measures as dependent variables and results are shown in Columns (2) to (5) of Table 4. None of the estimates are significantly different from zero and the threat of unobserved time varying factors affecting simultaneously the self-reported variables of the survey seems limited. ${ }^{9}$

Last, I check that the results reflect the French reform only, and not some broader macroeconomic trend. I do so by re-running the main regression on similar samples of workers in neighbouring countries, as the ECHP is harmonized across European countries. Data limitations restrict this comparison to Spain and Italy. ${ }^{10}$ The difference-in-differences estimates in these countries appear in Columns (6) and (7) of Table 4. Macroeconomic trends do not seem to drive the results for two reasons: the estimates are of different signs and they are not

\footnotetext{
${ }^{8}$ As an alternative test, I also checked whether the treatment effects for protected and unprotected workers influenced the weekly working hours and the monthly income. I re-run the regressions using these outcomes and the estimates are insignificant.

${ }^{9}$ The ECHP also records the satisfaction of workers with respect to different job characteristics (working hours, working time, earnings, working conditions, commuting) and none of these variables decreased significantly after the 1999 reform of the Delalande tax.

${ }^{10}$ Most of the necessary variables necessary to perform the analysis is not measured after 1997 in Germany, and the information in the last waves of the ECHP in Belgium is insufficient to accurately differentiate the public and private sectors.
} 
significantly different from zero.

\subsubsection{Discussing the Empirical Method}

Using individual fixed-effects means that the treatment effect is identified only if there are sufficient within-variations in the outcomes in the treated groups. This may be an issue because of scaling effects. While it turns out to be a minor concern as over $85 \%$ of treated workers experienced at least one within-variation in self-assessed health, I re-estimated the main results with a pooled OLS model in Column (1) of Table 5. The results are qualitatively similar.

As self-assessed health responses are on an ordinal scale, ordered response models might be thought more appropriate than ordinary least squares with individual fixed-effects. I reestimate the regressions via the ordered-logit model developed by Baetschmann et al. (2015). The results, in Column (2) of Table 5, do not differ significantly from the main results. ${ }^{11}$

The distribution of self-assessed health is skewed in the estimation sample (see Figure 3). This is commonly-found for self-assessed health measures. To ensure that the main results are not affected by this skewness, I re-estimate the effect of the reforms on the probability of having high self-assessed health (defined as having a "Good" or "Very Good" health). The results are consistent with those in the baseline (see Column (3) of Table 5).

\subsection{Adaptation}

According to Green (2015) and Caroli \& Godard (2016), nothing is known about the long term-impacts of perceived job security on health. Contributions in psychology argue that self-

\footnotetext{
${ }^{11}$ In a widely cited paper, Ai \& Norton (2003) show that the coefficient of an interaction term in case of nonlinear model is not informative per se. However, Puhani (2012) responds to Ai \& Norton (2003) and demonstrates that "the sign of the treatment effect in a nonlinear "difference-in-differences" model with a strictly monotonic transformation function of a linear index (like probit, logit or tobit) is equal to the sign of the coefficient of the interaction term" (p.87). This means that the sign of the interaction term is directly informative in our setting. Following again Puhani (2012), I bootstraped the standard errors. However, calculating marginal effects in ordered logit with individual fixed effect can only be done by assuming that individual fixed effects are zero (Karaca-Mandic et al. (2012)). This is conceptually paradoxical since the computation of marginal effects assumes homogeneity between individuals while the fundamental objective of the BUC estimator is to account for individual heterogeneity. Then, the results presented in column (2) are odd ratios.
} 
assessed measures of wellbeing are subject to hedonic adaptation (Frederick \& Loewenstein (1999). To explore the adaptation to the changes in perceived job insecurity I estimate the following regression:

$$
H_{i t}=\sum_{t=1998}^{2001} \gamma_{1}^{\prime}\left(P_{i} * \text { Wave }_{t}\right)+\sum_{t=1998}^{2001} \gamma_{2}^{\prime}\left(U_{i} * \text { Wave }_{t}\right)+\gamma_{3} X_{i t}+\alpha_{i}+\lambda_{t}+\epsilon_{i t}
$$

I estimate one coefficient per year, from the year of announcement to the last wave of the dataset. If unprotected workers adapted to the reform, the estimated coefficients should converge towards zero over time; without adaptation, the coefficients should remain significantly different from zero and of relatively similar size.

Figure 6 depicts the point estimates of the treatment effect year after year per treatment group. The absence of impact of the reform on health for protected workers holds whatever the year considered. The effect of the increase in job insecurity on unprotected workers' health is relatively steady over time and pairwise Wald tests confirm that the point estimates are of similar magnitude. The losses in health are not transitory and self-assessed health remains lower over a number of years.

\section{Conclusion}

I first present a theoretical model showing that linear fit between job security and health tends to overestimate (underestimate) the impact of gains (losses) in job security if loss aversion does apply to job security. I then use a large sample of European workers and confirm the existence of the loss aversion hypothesis: health does not respond to gains in job security while losses in job security predict significant losses in self-assessed health. I address endogeneity concerns by exploiting the 1999 change in the French Delalande tax, a firing tax restricted to older workers. This change translated into greater subjective job security for older workers but this exogenous rise in older workers' employment protection also reduced the relative firing cost of younger workers, leading to higher job insecurity for this group. I 
used difference-in-differences regressions to estimate separately the impact of exogenous gains and losses in job security on workers' health. I confirm the loss aversion hypothesis by showing that only losses in job security translate in significant losses in self-assessed health. Greater feelings of job security do not improve health. I show that these results are not driven by confounding shocks or other reforms and do not depend on the estimation method. I finally address a novel question in the literature by demonstrating that workers' health do not adapt over time to lower levels of job security.

The treatment effects of the Delalande tax are estimated among workers who stayed employed after the change in the Delalande tax scheme. As such, this article ignores the impact on health of workers who have been laid off because of the reform and may underestimate the detrimental impact of the reform in terms of health.

While I already mention that neglecting loss aversion in the relationship between job security and health biases empirical analysis, I should stress that considering the loss aversion hypothesis is also of policy relevance. As suggested by Layard (2006), loss aversion makes stabilization policy extremely important. Because of its policy relevance, studying systematically the loss aversion hypothesis in the relationship between job characteristics, individual choices and measures of wellbeing is a promising field for future researches. 


\section{References}

Abowd, J M, and F Kramarz. 2003. "The costs of hiring and separations." Labour Economics, 10: 499-530.

Ai, C, and E C Norton. 2003. "Interaction terms in logit and probit models." Economics letters, 80: $123-129$.

Baetschmann, G, K E Staub, and R Winkelmann. 2015. "Consistent estimation of the fixed effects ordered logit model." Journal of the Royal Statistical Society: Series A (Statistics in Society), 178: $685-703$.

Behaghel, L. 2007. "La protection de l'emploi des travailleurs âgés en France: une évaluation ex ante de la contribution Delalande." Annales d'Economie et de Statistique, 41-80.

Behaghel, L, B Crépon, and B Sédillot. 2004. "Contribution Delalande et transitions sur le marché du travail." Economie et statistique, 372: 61-88.

Biron, Caroline, Jean-Pierre Brun, Hans Ivers, and Cary Cooper. 2006. "At work but ill: psychosocial work environment and well-being determinants of presenteeism propensity." Journal of Public Mental Health, 5(4): 26-37.

Boles, Myde, Barbara Pelletier, and Wendy Lynch. 2004. "The relationship between health risks and work productivity." Journal of Occupational and Environmental Medicine, 46(7): 737-745.

Boyce, Christopher J, Alex M Wood, James Banks, Andrew E Clark, and Gordon DA Brown. 2013. "Money, well-being, and loss aversion: Does an income loss have a greater effect on well-being than an equivalent income gain?" Psychological science, 24(12): 2557-2562.

Burton, Wayne N, Alyssa B Schultz, Chin-Yu Chen, and Dee W Edington. 2008. "The association of worker productivity and mental health: a review of the literature." International Journal of Workplace Health Management, 1(2): 78-94.

Camerer, Colin, Daniel Kahneman, and Amos Tversky. 2000. "Prospect Theory in the Wild: Evidence from the Field." Choices, Values, and Frames, 288-300.

Caroli, Eve, and Mathilde Godard. 2016. "Does job insecurity deteriorate health?" Health economics, 25(2): 131-147.

Caverley, Natasha, J Barton Cunningham, and James N MacGregor. 2007. "Sickness presenteeism, sickness absenteeism, and health following restructuring in a public service organization." Journal of Management Studies, 44(2): 304-319.

Cheng, Grand H-L, and Darius K-S Chan. 2008. "Who suffers more from job insecurity? A meta-analytic review." Applied Psychology, 57(2): 272-303.

Clark, A E. 2001. "What really matters in a job? Hedonic measurement using quit data." Labour Economics, 8: 223-242.

Clark, A E, and F Postel-Vinay. 2009. "Job security and job protection." Oxford Economic Papers, 61: 207-239.

Clark, Andrew E. 1999. "Are wages habit-forming? Evidence from micro data." Journal of Economic Behavior \&5 Organization, 39(2): 179-200.

Di Tella, Rafael, John Haisken-De New, and Robert MacCulloch. 2010. "Happiness adaptation to income and to status in an individual panel." Journal of Economic Behavior E3 Organization, $76(3): 834-852$. 
Doiron, Denise, Denzil G Fiebig, Meliyanni Johar, and Agne Suziedelyte. 2015. "Does self-assessed health measure health?" Applied Economics, 47(2): 180-194.

Duijts, Saskia FA, Ijmert Kant, Gerard MH Swaen, Piet A van den Brandt, and Maurice PA Zeegers. 2007. "A meta-analysis of observational studies identifies predictors of sickness absence." Journal of clinical epidemiology, 60(11): 1105-1115.

Frederick, Shane, and George Loewenstein. 1999. "Hedonic Adaptation." Well-Being. The foundations of Hedonic Psychology/Eds. D. Kahneman, E. Diener, N. Schwarz. NY: Russell Sage, 302329 .

Georgieff, Alexandre, and Anthony Lepinteur. 2018. "Partial employment protection and perceived job security: evidence from France." Oxford Economic Papers, 70(3): 846-867.

Gilbert, Daniel T, Carey K Morewedge, Jane L Risen, and Timothy D Wilson. 2004. "Looking forward to looking backward: The misprediction of regret." Psychological Science, 15(5): 346350 .

Green, Francis. 2015. "Health effects of job insecurity." IZA World of labor.

Grund, Christian, and Dirk Sliwka. 2007. "Reference-dependent preferences and the impact of wage increases on job satisfaction: Theory and evidence." Journal of Institutional and Theoretical Economics JITE, 163(2): 313-335.

Johns, Gary. 2002. "Absenteeism and mental health." Handbook of mental health in the workplace, 437-455.

Johns, Gary. 2010. "Presenteeism in the workplace: A review and research agenda." Journal of Organizational Behavior, 31(4): 519-542.

Kahneman, Daniel, and Amos Tversky. 1979. "Prospect Theory: An Analysis of Decision under Risk." Econometrica, 47(2): 263-292.

Karaca-Mandic, P, E C Norton, and B Dowd. 2012. "Interaction terms in nonlinear models." Health services research, 47: 255-274.

Kermer, Deborah A, Erin Driver-Linn, Timothy D Wilson, and Daniel T Gilbert. 2006. "Loss aversion is an affective forecasting error." Psychological science, 17(8): 649-653.

László, Krisztina D, Hynek Pikhart, Mária S Kopp, Martin Bobak, Andrzej Pajak, Sofia Malyutina, Gyöngyvér Salavecz, and Michael Marmot. 2010. "Job insecurity and health: a study of 16 European countries." Social science $\mathscr{E}$ medicine, 70(6): 867-874.

Layard, Richard. 2006. "Happiness and public policy: A challenge to the profession." The Economic Journal, 116(510).

Lepinteur, Anthony. 2018. "The shorter workweek and worker wellbeing: Evidence from Portugal and France." Labour Economics.

Mills, Peter R. 2005. "The development of a new corporate specific health risk measurement instrument, and its use in investigating the relationship between health and well-being and employee productivity." Environmental Health, 4(1): 1.

Mills, Peter R, Ronald C Kessler, John Cooper, and Sean Sullivan. 2007. "Impact of a health promotion program on employee health risks and work productivity." American Journal of Health Promotion, 22(1): 45-53. 
Nickell, Stephen. 1981. "Biases in dynamic models with fixed effects." Econometrica: Journal of the Econometric Society, 1417-1426.

Puhani, P A. 2012. "The treatment effect, the cross difference, and the interaction term in nonlinear "difference-in-differences" models." Economics Letters, 115: 85-87.

Rick, Scott. 2011. "Losses, gains, and brains: Neuroeconomics can help to answer open questions about loss aversion." Journal of Consumer Psychology, 21(4): 453-463.

Stewart, Walter F, Judith A Ricci, Elsbeth Chee, David Morganstein, and Richard Lipton. 2003a. "Lost productive time and cost due to common pain conditions in the US workforce." Jama, 290(18): 2443-2454.

Stewart, Walter F, Judith A Ricci, Elsbeth Chee, Steven R Hahn, and David Morganstein. 2003b. "Cost of lost productive work time among US workers with depression." Jama, 289(23): 3135-3144.

Sverke, Magnus, Johnny Hellgren, and Katharina Näswall. 2002. "No security: a metaanalysis and review of job insecurity and its consequences." Journal of occupational health psychology, $7(3): 242$. 


\section{Figures and Tables}

Figure 1: Distribution of Self-Assessed Health and Perceived Job Security - Estimation Sample 1
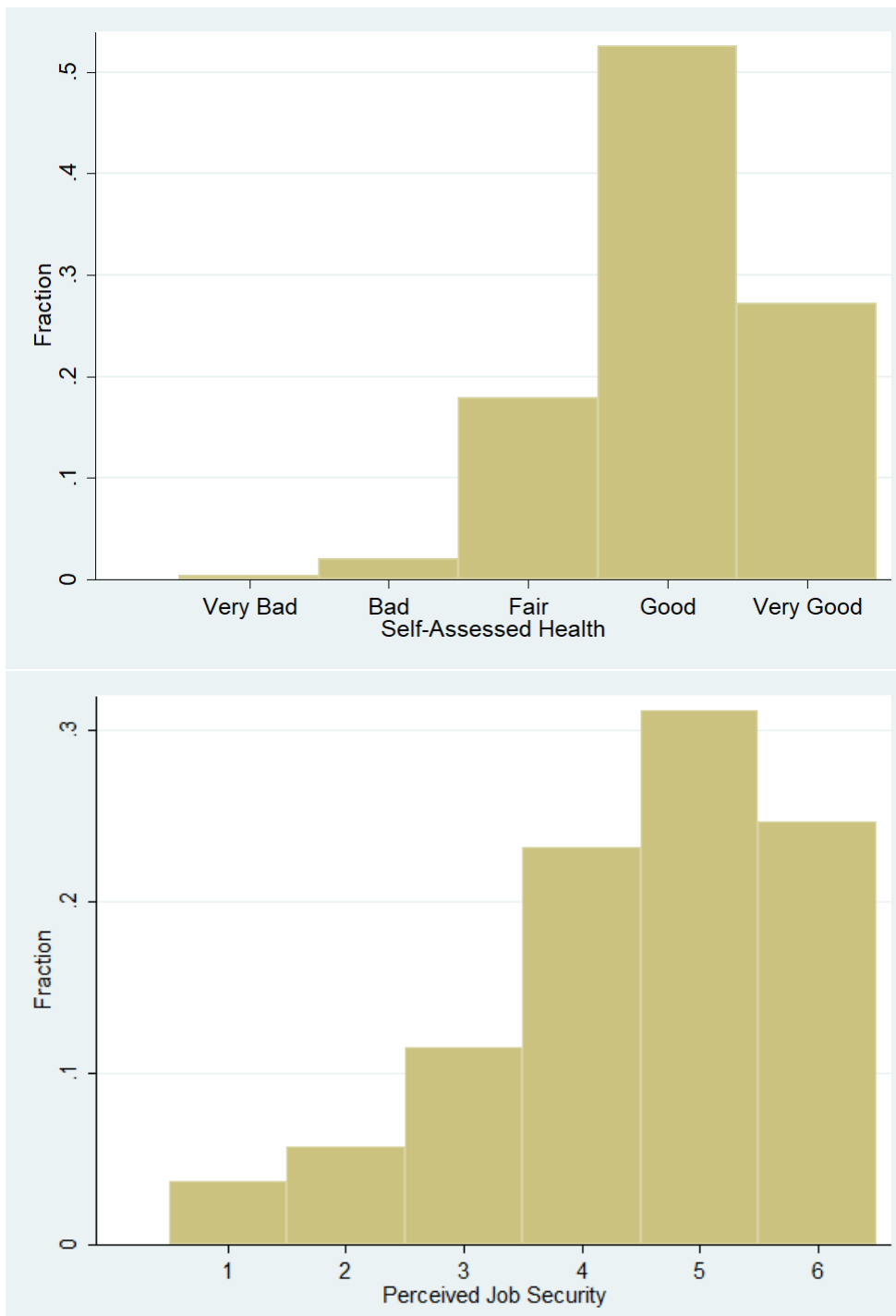

Source: ECHP - Estimation Sample 1. 
Figure 2: Mean Change in Health as a Function of Change in Perceived Job Security

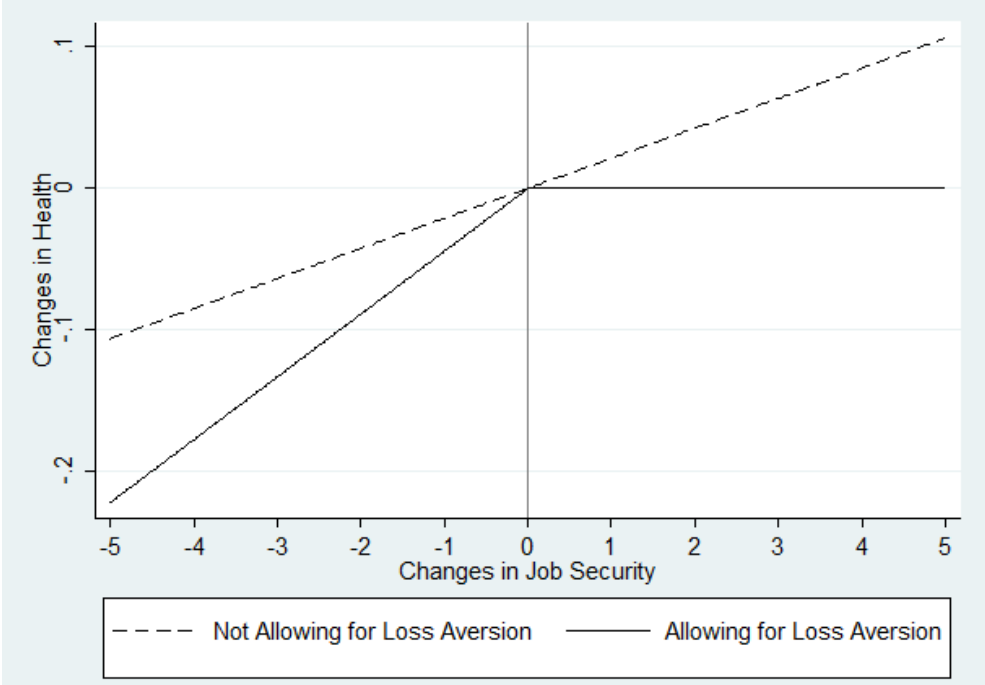

Source: ECHP - Estimation Sample 1.

Note: The dashed line uses the estimate in Column (1) of Table 1 (coef. $=0.022$, s.e. $=0.001$ ). The solid line uses the estimates in Column (2) of Table 1 (coef. $=0.001$, s.e. $=0.002$ and coef. $=0.045$, s.e. $=0.002$ ). 
Figure 3: Distribution of Self-Assessed Health and Perceived Job Security - Estimation Sample 2
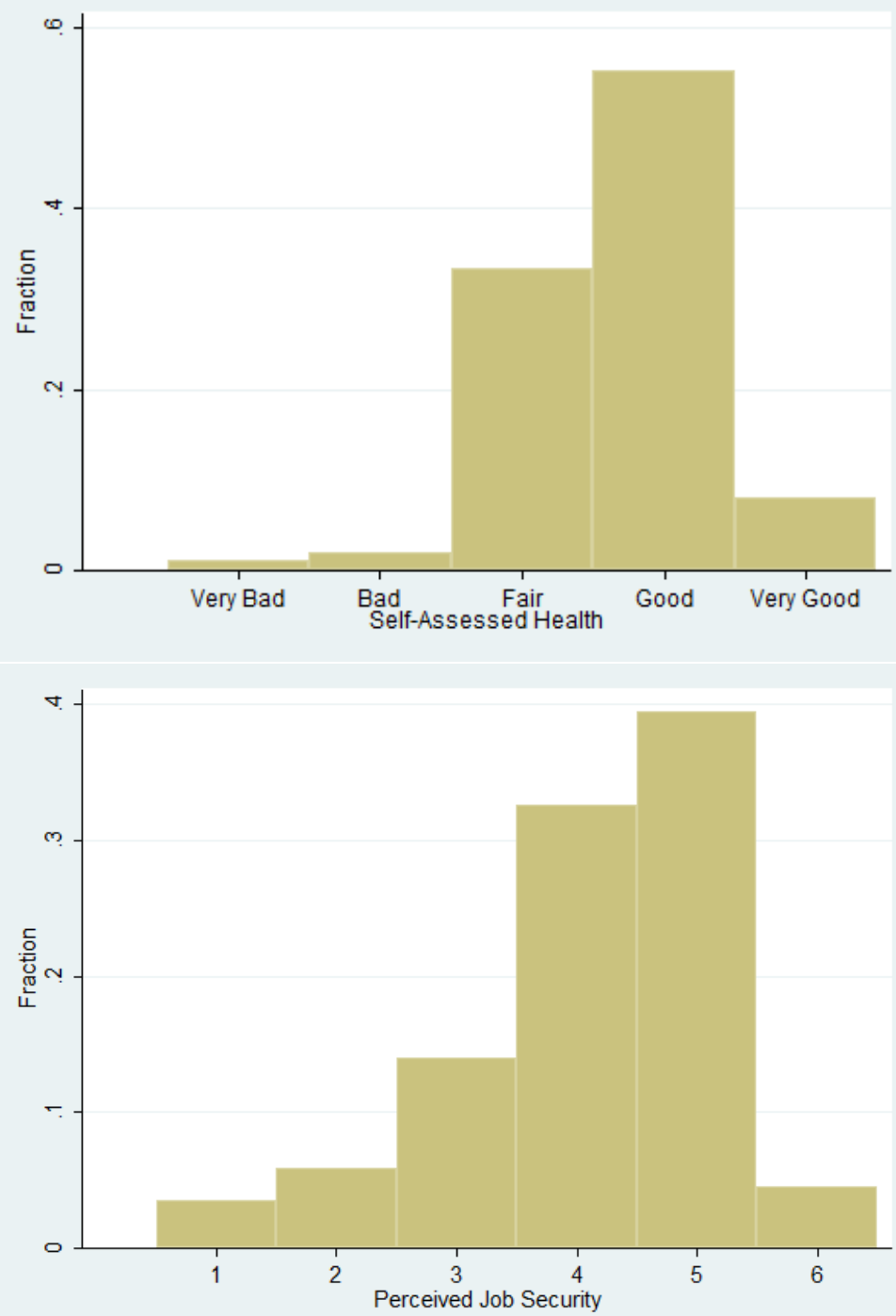

Source: ECHP - Estimation Sample 2. 
Figure 4: Evolution of the Average Self-Assessed Health - Treatment and Control Groups

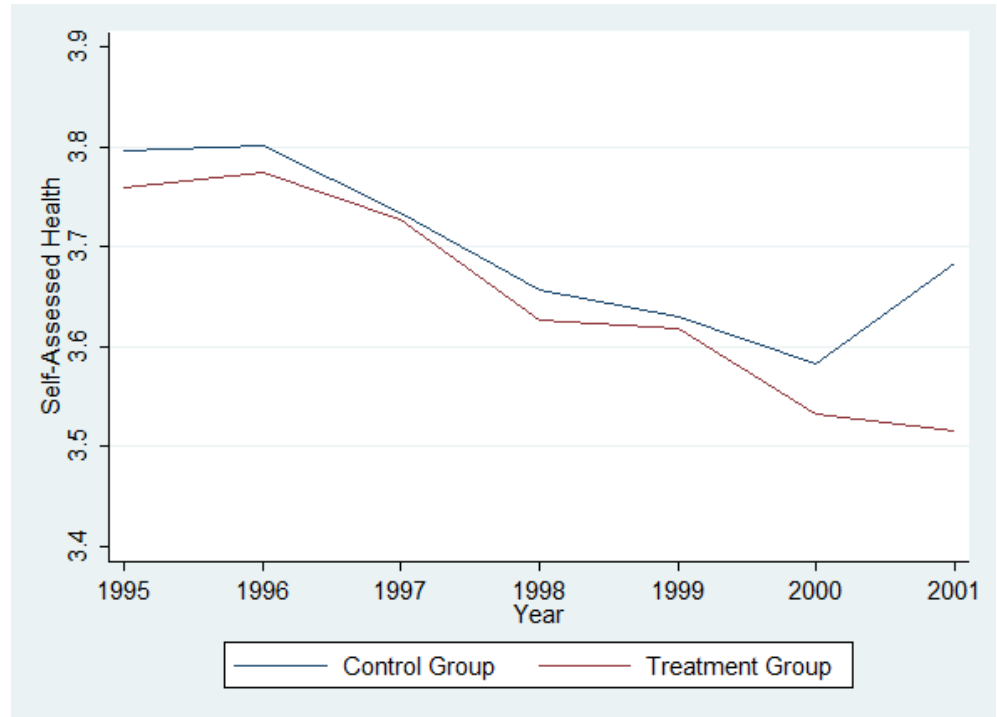

Source: ECHP - Estimation Sample 2.

Figure 5: Evolution of the Average Self-Assessed Health - Younger and Older Workers in Treatment Group and Control Group

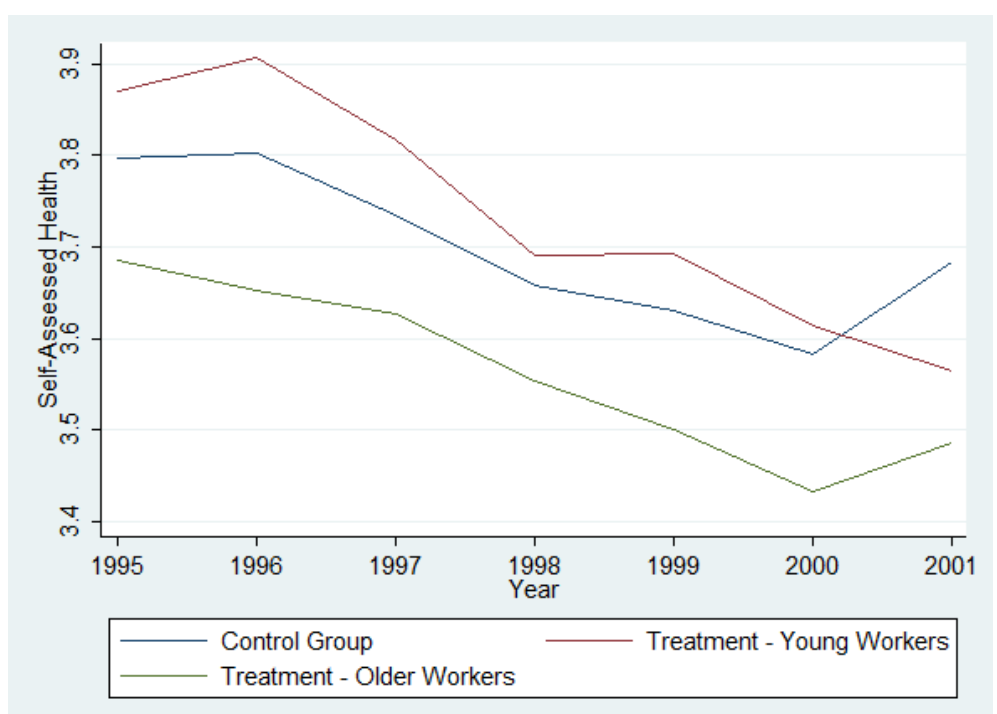

Source: ECHP - Estimation Sample 2.

Note: Younger workers and older workers in treatment are respectively the unprotected and protected workers in treated firms. 
Figure 6: Adaptation to the Reform by Treatment Groups

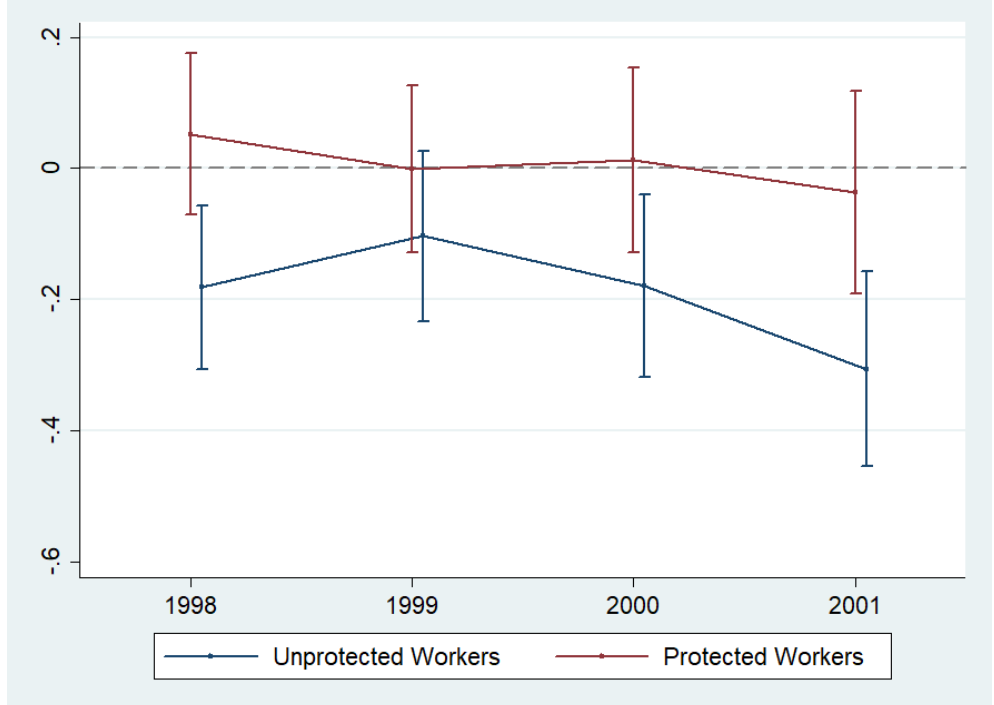

Source: ECHP - Estimation Sample 2. 
Table 1: Health and changes in Perceived Job Security: OLS Results and Robustness Checks - All Countries

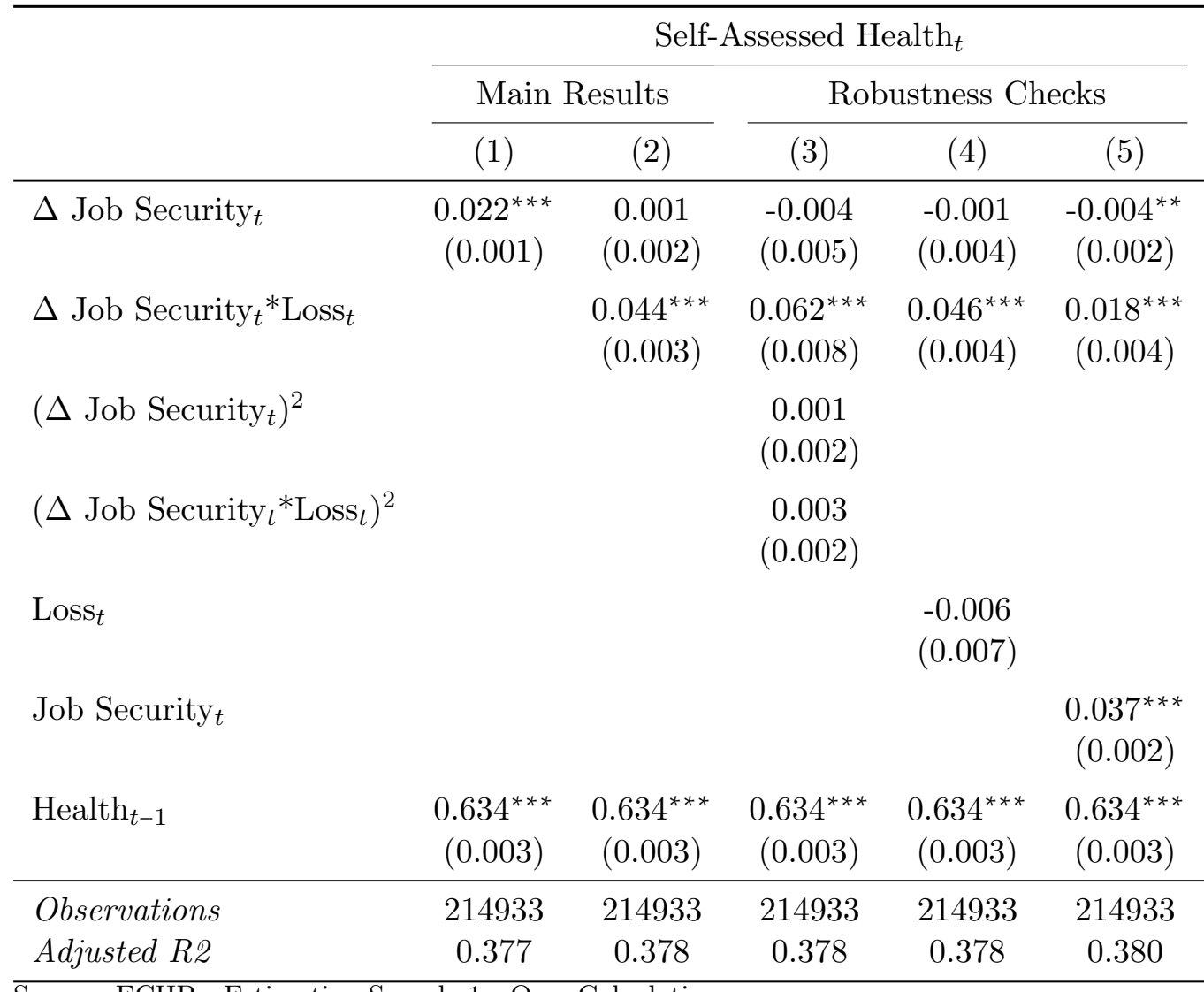

Source: ECHP - Estimation Sample 1 - Own Calculations.

Notes: The standard errors in parentheses are clustered at the individual level. The controls include the age, the age squared, dummies for marital status, children in the household, the monthly wage (in log), the weekly working time, the contract type (permanent vs. temporary), the region fixed-effects, country fixed-effects and changes from one year to the next in marital status, in the household size, in the monthly wage (in log), in the weekly working time and in the contract type. $* * *, * * *$ indicate significance at the $10 \%, 5 \%$ and $1 \%$ levels respectively. 
Table 2: The Delalande Tax scheme

\begin{tabular}{|c|c|c|c|c|c|c|c|c|c|c|}
\hline & \multicolumn{9}{|c|}{ Worker's age } \\
\hline & & 50 & 51 & 52 & 53 & 54 & 55 & $56-57$ & 58 & 59 \\
\hline July 1987-June 1992 & All firm sizes & & & & & & 3 & 3 & 3 & 3 \\
\hline \multirow[t]{2}{*}{ July 1992 - Dec. 1992} & More than 20 employees & 1 & 1 & 2 & 2 & 4 & 5 & 6 & 6 & 6 \\
\hline & Less than 20 employees & 0.5 & 0.5 & 1 & 1 & 2 & 2.5 & 3 & 3 & 3 \\
\hline Jan 1993-Dec 1998 & All firm sizes & 1 & 1 & 2 & 2 & 4 & 5 & 6 & 6 & 6 \\
\hline \multirow[t]{2}{*}{ After January 1999} & More than 50 employees & 2 & 3 & 5 & 6 & 8 & 10 & 12 & 10 & 8 \\
\hline & Less than 50 employees & 1 & 1 & 2 & 2 & 4 & 5 & 6 & 6 & 6 \\
\hline
\end{tabular}

Notes: For each age group, the table displays the tax due by the firm to the unemployment insurance system if it lays the worker off. The tax is a function of previous wages, and is stated in months of gross wage. 
Table 3: The Rise in the Delalande Tax and Self-Assessed Health: Panel Results

Self-Assessed Health

\begin{tabular}{|c|c|c|c|c|c|}
\hline & \multicolumn{5}{|c|}{ Self-Assessed Health } \\
\hline & (1) & $(2)$ & (3) & $(4)$ & $(5)$ \\
\hline Population Effect & $\begin{array}{l}-0.074 \\
(0.047)\end{array}$ & & & & \\
\hline \multicolumn{6}{|l|}{ Protected Workers: } \\
\hline Treatment Effect & & $\begin{array}{l}-0.048 \\
(0.061)\end{array}$ & $\begin{array}{l}-0.037 \\
(0.070)\end{array}$ & & \\
\hline Anticipation Effect & & & $\begin{array}{c}0.009 \\
(0.078)\end{array}$ & & \\
\hline Total Effect & & & & $\begin{array}{l}-0.021 \\
(0.064)\end{array}$ & \\
\hline Placebo Effect & & & & & $\begin{array}{c}0.009 \\
(0.082)\end{array}$ \\
\hline \multicolumn{6}{|l|}{ Unprotected Workers: } \\
\hline Treatment Effect & & $\begin{array}{l}-0.097 \\
(0.061)\end{array}$ & $\begin{array}{c}-0.147^{* *} \\
(0.069)\end{array}$ & & \\
\hline Anticipation Effect & & & $\begin{array}{c}-0.139^{*} \\
(0.071)\end{array}$ & & \\
\hline Total Effect & & & & $\begin{array}{c}-0.147^{* *} \\
(0.061)\end{array}$ & \\
\hline Placebo Effect & & & & & $\begin{array}{l}-0.058 \\
(0.093)\end{array}$ \\
\hline Observations & 4202 & 4202 & 4202 & 4202 & 1789 \\
\hline Individuals & 700 & 700 & 700 & 700 & 700 \\
\hline Within R2 & 0.037 & 0.037 & 0.038 & 0.038 & 0.011 \\
\hline
\end{tabular}

Source: ECHP - Estimation Sample 2 - Own Calculations.

Notes: The standard errors in parentheses are clustered at the individual level. The controls include the age squared, dummies for marital status, children in the household, region fixed-effects, year fixed-effects and individual fixed-effects. *, **, *** indicate significance at the $10 \%, 5 \%$ and $1 \%$ levels respectively. 


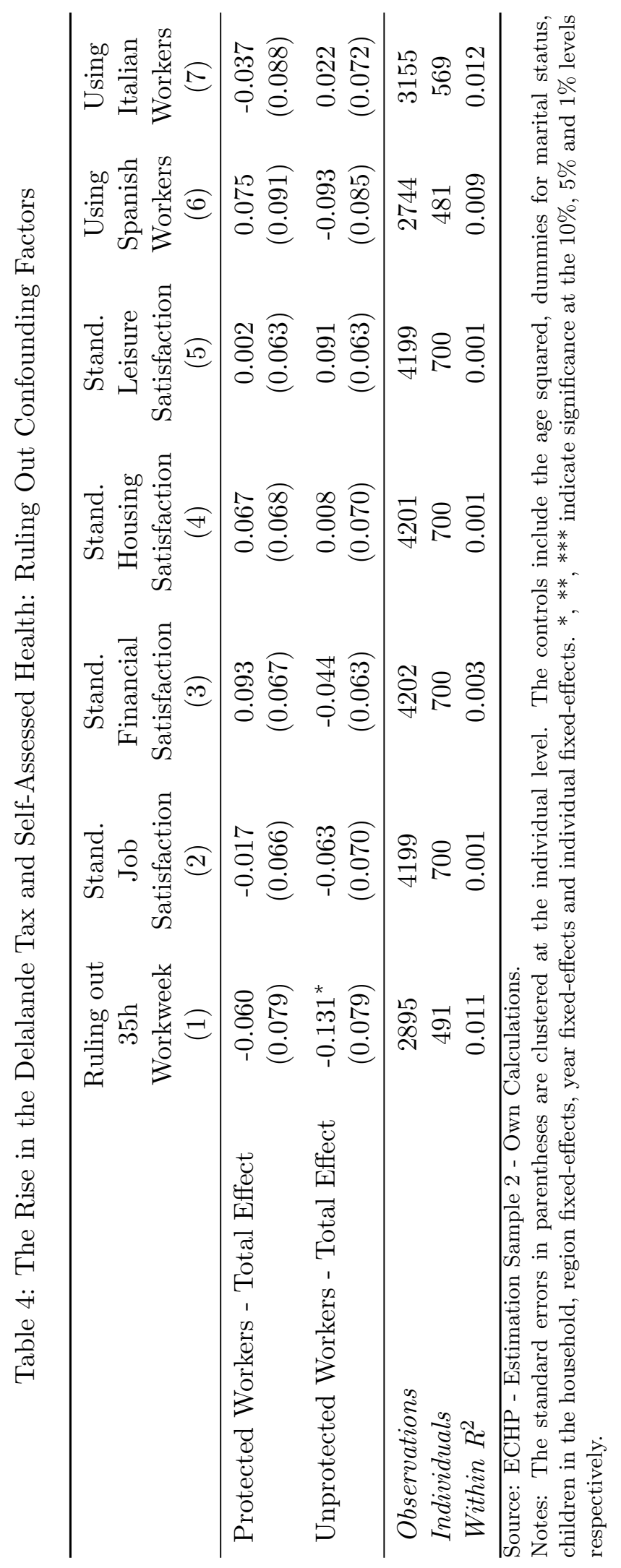


Table 5: The Rise in the Delalande Tax and Self-Assessed Health: Robustness Checks

\begin{tabular}{lccc}
\hline & OLS & BUC & Logit \\
& $(1)$ & $(2)$ & $\begin{array}{c}\text { High } \\
\text { Health Status } \\
(3)\end{array}$ \\
\hline Protected Workers - Total Effect & -0.048 & -0.042 & -0.001 \\
& $(0.064)$ & $(0.228)$ & $(0.036)$ \\
Unprotected Workers - Total Effect & $-0.103^{*}$ & $-0.522^{* *}$ & $-0.076^{* *}$ \\
& $(0.061)$ & $(0.215)$ & $(0.035)$ \\
\hline Observations & 4202 & 14110 & 4202 \\
Individuals & 700 & 700 & 700 \\
Adjusted R & 0.038 & - & - \\
Log Pseudo-Likelihood & - & -1636.8 & - \\
Within $R^{2}$ & - & - & 0.014 \\
\hline Sor & & &
\end{tabular}

Source: ECHP - Estimation Sample 2 - Own Calculations.

Notes: The standard errors in parentheses are clustered at the individual level. The controls include the age squared, dummies for marital status, children in the household, region fixed-effects, year fixed-effects and individual fixed-effects (except in Column (1)). The number of observations per individual increases artificially in the column (2) because of the use of the "Blow-Up and Cluster" estimator (see Baetschmann et al. (2015) for technical details). *, **, *** indicate significance at the $10 \%, 5 \%$ and $1 \%$ levels respectively. 


\section{Appendix}

Figure A.1: Distribution of Changes in Perceived Job Security - Estimation Sample 1

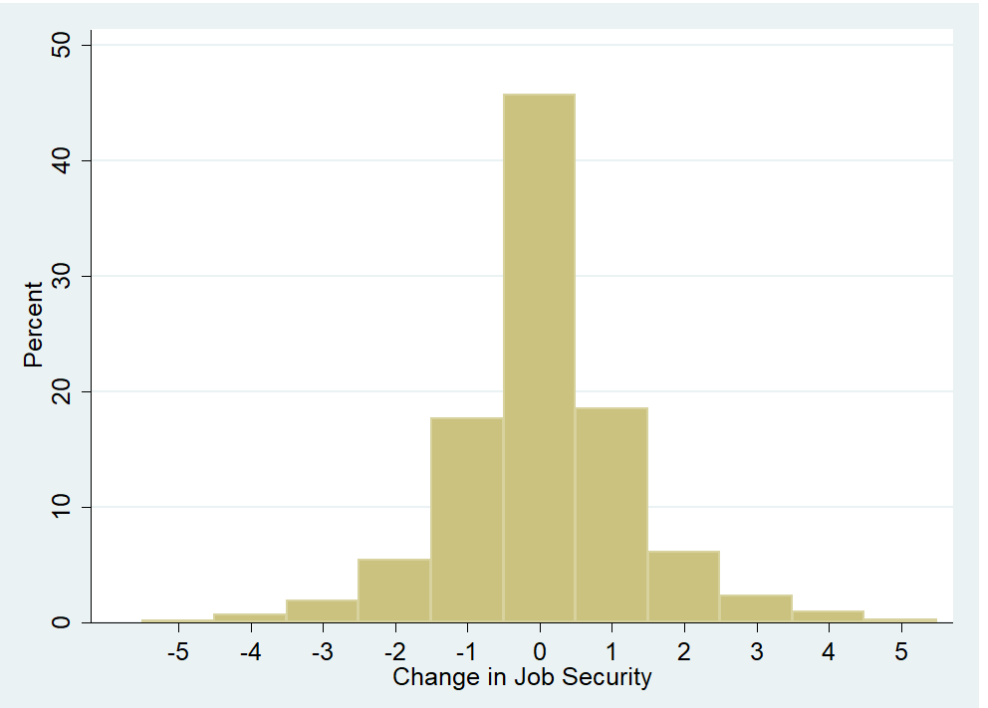

Source: ECHP - Estimation Sample 1

Note: $45.70 \%$ of the estimation sample did not report change in job security while $25.99 \%$ and $28.31 \%$ of the sample respectively reported losses and gains in job security. 
Table A.1: Descriptive Statistics - Estimation Sample 1

\begin{tabular}{lcc}
\hline & Mean & SD \\
\hline Outcomes: & 4.042 & 0.750 \\
Self-Assessed Health [1-5] & 4.463 & 1.328 \\
Perceived Job Security [1-6] & & \\
Individual characteristics: & 39.020 & 9.998 \\
Age & 0.418 & 0.493 \\
Female (\%) & 0.664 & 0.472 \\
Married (\%) & 0.013 & 0.112 \\
Separated (\%) & 0.045 & 0.3208 \\
Divorced (\%) & 0.012 & 0.108 \\
Widowed (\%) & 0.266 & 0.442 \\
Never Married (\%) & & \\
Job characteristics: & 9.569 & 1.800 \\
Personal Labour Income (log) & 38.681 & 8.535 \\
Weekly Working Hours & & \\
Geographic Composition: & 0.132 & 0.338 \\
France (\%) & 0.142 & 0.349 \\
Italy (\%) & 0.120 & 0.325 \\
The Netherlands (\%) & 0.068 & 0.252 \\
Belgium (\%) & 0.049 & 0.217 \\
Ireland (\%) & 0.111 & 0.314 \\
Spain (\%) & 0.116 & 0.321 \\
Portugal (\%) & 0.056 & 0.229 \\
Finland (\%) & 0.069 & 0.253 \\
Greece (\%) & 0.070 & 0.255 \\
Denmark (\%) & 0.067 & 0.249 \\
Austria (\%) & 55,657 & - \\
\hline Ondividuals & $-0 w n$ Calculations. \\
Source: ECHP - Estimation Sample 1 & \\
\hline
\end{tabular}




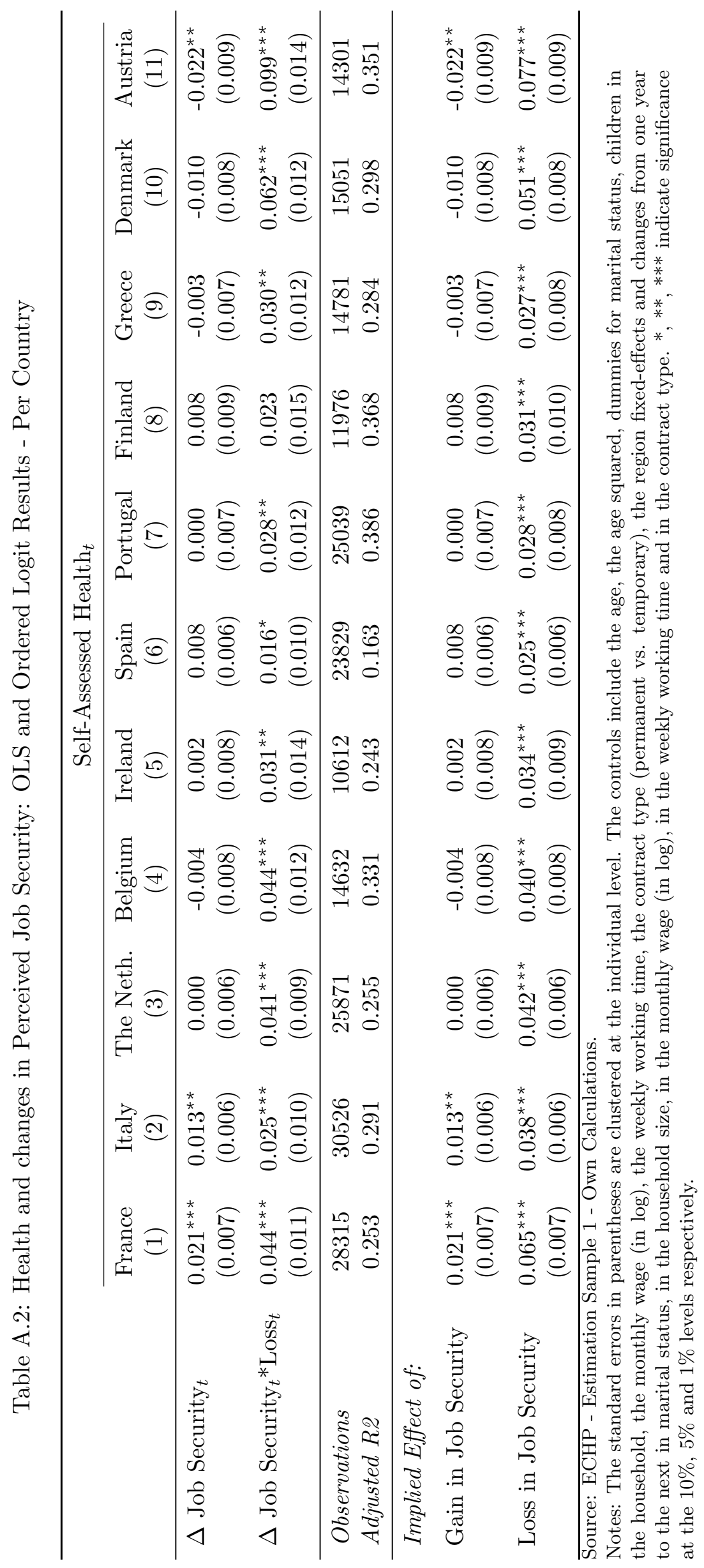


Table A.3: Health and changes in Perceived Job Security: OLS Results - BHPS and SOEP

\begin{tabular}{lccccc}
\hline & \multicolumn{3}{c}{ Self-Assessed Health } \\
\cline { 2 - 3 } \cline { 5 - 6 } \cline { 5 - 6 } & \multicolumn{2}{c}{ BHPS } & & \multicolumn{2}{c}{ SOEP } \\
\cline { 2 - 3 } \cline { 5 - 6 }$\Delta$ Job Security & $0.019^{* * *}$ & 0.001 & & $0.040^{* * *}$ & 0.000 \\
& $(0.002)$ & $(0.004)$ & & $(0.003)$ & $(0.005)$ \\
$\Delta$ Job Security*Loss & & $0.039^{* * *}$ & & $0.080^{* * *}$ \\
& & $(0.003)$ & & $(0.008)$ \\
$\Delta$ Health_t-1 & $0.395^{* * *}$ & $0.395^{* * *}$ & $0.634^{* * *}$ & $0.631^{* * *}$ \\
& $(0.003)$ & $(0.003)$ & & $(0.004)$ & $(0.004)$ \\
\hline Observations & 57968 & 57968 & & 169792 & 169792 \\
Adjusted R2 & 0.298 & 0.299 & 0.336 & 0.337 \\
\hline
\end{tabular}

Source: BHPS and SOEP - Own Calculations.

Notes: The standard errors in parentheses are clustered at the individual level. The controls include the age, the age squared, dummies for marital status, children in the household, the monthly wage (in log), the weekly working time, the contract type (permanent vs. temporary), the region fixed-effects and changes from one year to the next in marital status, in the household size, in the monthly wage (in $\log$ ), in the weekly working time and in the contract type. $*, * *, * * *$ indicate significance at the $10 \%, 5 \%$ and $1 \%$ levels respectively. 
Table A.4: Descriptive Statistics - Estimation Sample 2

\begin{tabular}{lcc}
\hline & Mean & SD \\
\hline Outcomes: & 3.669 & 0.707 \\
Self-Assessed Health [1-5] & 4.122 & 1.120 \\
Perceived Job Security [1-6] & & \\
Individual characteristics: & 47.515 & 4.754 \\
Age & 0.363 & 0.480 \\
Female (\%) & 0.789 & 0.408 \\
Married (\%) & 0.007 & 0.081 \\
Separated (\%) & 0.103 & 0.304 \\
Divorced (\%) & 0.026 & 0.158 \\
Widowed (\%) & 0.076 & 0.265 \\
Never Married (\%) & 0.269 & 0.443 \\
Children in the HH (\%) & & \\
Job characteristics: & 9.173 & 0.539 \\
Personal Labour Income (log) & \\
Weekly Working Hours & 36.507 & 15.923 \\
Years of Experience & 13.909 & 6.137 \\
Treated Firms (\%) & 0.527 & 0.499 \\
\hline Observations & 4202 & - \\
Individuals & 700 & - \\
\hline Source: ECHP - Estimation Sample 2 - Own Calculations.
\end{tabular}


Table A.5: The Rise in the Delalande Tax and Perceived Job Security: Panel Results

\begin{tabular}{|c|c|c|c|c|}
\hline & \multicolumn{4}{|c|}{ Perceived Job Security } \\
\hline & $(1)$ & $(2)$ & $(3)$ & $(4)$ \\
\hline Population Effect & $\begin{array}{c}-0.018 \\
(0.043)\end{array}$ & & & \\
\hline \multicolumn{5}{|l|}{ Protected Workers: } \\
\hline Treatment Effect & & $\begin{array}{l}0.128^{* *} \\
(0.055)\end{array}$ & $\begin{array}{l}0.156^{* *} \\
(0.061)\end{array}$ & \\
\hline Anticipation Effect & & & $\begin{array}{c}0.081 \\
(0.070)\end{array}$ & \\
\hline Total Effect & & & & $\begin{array}{l}0.121^{* *} \\
(0.055)\end{array}$ \\
\hline \multicolumn{5}{|c|}{ Unprotected Workers: } \\
\hline Treatment Effect & & $\begin{array}{c}-0.152^{* * *} \\
(0.053)\end{array}$ & $\begin{array}{c}-0.168^{* * *} \\
(0.061)\end{array}$ & \\
\hline Anticipation Effect & & & $\begin{array}{l}-0.070 \\
(0.064)\end{array}$ & \\
\hline Total Effect & & & & $\begin{array}{c}-0.126^{* *} \\
(0.061)\end{array}$ \\
\hline Observations & 4202 & 4202 & 4202 & 4202 \\
\hline Individuals & 700 & 700 & 700 & 700 \\
\hline Within R2 & 0.024 & 0.024 & 0.024 & 0.023 \\
\hline
\end{tabular}

Source: ECHP - Estimation Sample 2 - Own Calculations.

Notes: The standard errors in parentheses are clustered at the individual level. The controls include the age squared, dummies for marital status, children in the household, region fixed-effects, year fixed-effects and individual fixed-effects. $*, * *, * * *$ indicate significance at the $10 \%, 5 \%$ and $1 \%$ levels respectively. 